\title{
O TRABALHO DO PSICÓLOGO COM GRUPO DE ADOLESCENTES EM PRIVAÇÃO DE LIBERDADE
}

\author{
Giulia Oliva Grassi \\ Universidade Federal de Santa Catarina \\ Beatriz Pires Coltro \\ Universidade Federal de Santa Catarina
}

Andréia Isabel Giacomozzi

Universidade Federal de Santa Catarina

Tathiana Reche Santa Rosa

Departamento de Administração Socioeducativo de Santa Catarina

\begin{abstract}
Resumo
Nas políticas de atendimento aos adolescentes em conflito com a lei, evidencia-se a presença obrigatória do psicólogo nas equipes multidisciplinares de atendimento socioeducativo, cabendo a esses profissionais diferentes formas de atuar e, sobretudo a reflexão sobre o seu papel nesse sistema. Assim, este artigo discute a intervenção psicológica com grupos de adolescentes nas unidades de privação de liberdade a partir de um relato de experiência. Notou-se a necessidade entre os adolescentes de compartilharem as suas experiências com drogas, violência e tráfico, aspectos que constituem o que chamam de "mundo do crime". Assim, entende-se fundamental para a coordenação de grupo com adolescentes em privação de liberdade o reconhecimento de suas histórias e experiências, considerando a postura ética que o profissional psicólogo deve assumir ao conduzir o trabalho grupal, cujo objetivo central é proporcionar um espaço de acolhida para discussão e reflexão coletivas.
\end{abstract}

Palavras-chave: grupo; adolescentes em conflito com a lei; medidas socioeducativas.

\section{THE PSYCHOLOGIST'S WORK WITH A GROUP OF ADOLESCENTS IN DEPRIVATION OF LIBERTY}

\begin{abstract}
The policies for the adolescent offenders' care presume the presence of psychologists in the multidisciplinary teams of socio-educational assistance, being up to these professionals different ways of acting and the reflection on their role in this system. Therefore, this paper discusses the coordination psychological intervention of groups with adolescents in detention units based on an experience report. One can notice the need among these adolescents to report their experiences with drugs, violence and drug trafficking, which constitute what they call the "world of crime". Thus, it is fundamental for the group coordination with adolescents in deprivation of liberty to recognize their histories and experiences, taking into account the ethical stance that the psychologist must assume when conducting the group session, which main goal is to provide an acceptance space for collective discussion and reflection.
\end{abstract}

Key words: group; adolescent offenders; socioeducative measures. 


\title{
EL TRABAjo DEL PSICólogo CON EL GRUPO DE ADOLESCENTES EN PRIVACIÓN DE LIBERTAD
}

\begin{abstract}
Resumen
En las políticas de atención a los adolescentes en conflicto con la ley, se evidencia la presencia obligatoria del psicólogo en los equipos multidisciplinares de atención socioeducativa, teniendo en cuenta las diferentes formas de actuar de estos profesionales y, especialmente, la reflexión sobre su papel en ese sistema. Así, este manuscrito discute la intervención psicológica con grupos de adolescentes en las unidades de privación de libertad a partir de un relato de experiencia. Se notó la necesidad entre los adolescentes de relatar sus experiencias con drogas, violencia y tráfico, puntos que constituyen lo que llaman de "mundo del crimen". Así, se considera fundamental para la coordinación de grupo con adolescentes en privación de libertad el reconocimiento de sus historias y experiencias, considerando la postura ética que el profesional psicólogo debe asumir al realizar el trabajo grupal, cuyo objetivo central es proporcionar un espacio de acogida, discusión y reflexión.
\end{abstract}

Palabras clave: grupo, adolescentes en conflicto con la ley, medidas socioeducativas.

\section{INTRODUÇÃO}

A atuação com os adolescentes em conflito com a lei representa um grande desafio e um longo caminho a ser trilhado pelos pesquisadores e profissionais que trabalham com esse tema. Diversos autores se debruçam sobre a temática e fundamentam o que tem composto a realidade brasileira nesse campo (Bazon, Silva \& Ferrari, 2013; Conceição, Penso, Costa \& Carreteiro, 2016; Ferrão, Santos \& Dias, 2016; Gomes \& Conceição, 2014; Mourão \& Silveira, 2014; Nardi \& Dell'Aglio, 2014; Silva, 2015; Tomasi \& Macedo, 2015; Waiselfisz, 2014; Waiselfisz, 2015). No entanto, o contexto de Santa Catarina permanece pouco explorado no que diz respeito ao trabalho com adolescentes em privação de liberdade e os trabalhos sobre intervenções grupais estão focalizados, principalmente, no cumprimento de medidas em meio aberto nos Centros de Referência Especializado em Assistência Social- CREAS (Schmitt, Nascimento \& Schweitzer, 2016).

Com o intuito de tornar visível a realidade das intervenções psicológicas em unidades de privação de liberdade, o presente artigo discute de maneira crítica e reflexiva o trabalho grupal com adolescentes em cumprimento de medida socioeducativa em um centro de atendimento socioeducativo, a partir de um relato de experiência do estágio em Psicologia.

De acordo com o último levantamento do Sistema de Atendimento Socioeducativo (SINASE) (Brasil, 2017), em Santa Catarina, o número de adolescentes e jovens em restrição e privação de liberdade em 2014 foi de 294. Destes, 103 estavam internados, 155 em regime de internação provisória e 36 em semiliberdade. Sobre o perfil de adolescentes brasileiros que cumpriam medidas socioeducativas de restrição ou privação de liberdade, o supracitado levantamento destaca que a maioria era do sexo masculino (95\%), com idade entre 16 e 17 anos (56\%) e negro (55,77\%). Essas categorias interseccionais que compõem o grupo de adolescentes em cumprimento de medidas 
socioeducativas e, por consequência, sua relação com atos infracionais, revela o perfil de vulnerabilidade de uma parcela da população que sofre a ressonância das consequências do abandono e omissão das políticas públicas e sociais.

O processo de exclusão social de alguns setores da população ao longo do desenvolvimento político e econômico no Brasil, assim como em diversos países da América Latina, é resultado de um modelo de ideal social que se estrutura a partir do impedimento ao acesso a bens de consumo e políticas públicas às populações marginalizadas (Véras, 2001), nomeadamente a população negra, sem-terra, em situação de pobreza e baixa escolaridade. Dessa maneira, tanto a pobreza, quanto a marginalidade, funcionam como marcadores sociais que constituem modos de subjetivação e identidades.

Esse processo de exclusão social é vivido com resistência, principalmente por adolescentes e jovens que buscam o reconhecimento de seus pares e aspiram acessar aos bens materiais e de consumo disponíveis (Pereira \& Gurski, 2014). As estratégias oferecidas pelo Estado não são suficientes ou satisfatórias, principalmente as vinculadas ao controle social (Carvalho \& Silva, 2011), e os programas de proteção e seguridade social não dão conta das necessidades que são apresentadas diariamente pelos adolescentes. Assim, uma saída possível passa a ser a adoção de práticas ilícitas e/ou arriscadas, como o consumo de álcool e outras drogas; e a realização de atos infracionais, configurando uma situação de total desfiliação, sem emprego formal, fora do alcance dos atendimentos públicos e abandonado em termos relacionais (Castel, 1997).

Observa-se, portanto, que a adolescência, marcadamente definida pelo seu caráter de desenvolvimento psicossocial e de construção identitária (Frota, 2007), não está isenta dos processos estruturais que marginalizam, excluem e imprimem vivências de violência e negligência. Como forma de controle social, Guareschi, Reis, Huning e Bertuzzi (2007) apontam para a fragilidade das medidas tomadas pelo Estado no sentido de tornar esses jovens "úteis" de alguma forma, pressupondo uma relação entre inutilidade e pobreza e a necessidade do enquadramento no sistema socioeconômico vigente.

A chegada dos adolescentes ao SINASE e às instituições que operam o atendimento socioeducativo é posterior ao processo estrutural de exclusão social e marginalização que opera na história do Brasil. Em 2012, o Estado decretou a instituição do Sistema Nacional de Atendimento Socioeducativo (Brasil, 2012), que se aprofunda nas medidas de socioeducação, estendendo as ações preconizadas pelo Estatuto da Criança e Adolescente (ECA) e estabelecendo parâmetros para o cumprimento de tais medidas pelos adolescentes autores de atos infracionais.

O atendimento psicológico faz parte das medidas protetivas para os menores de 18 anos (Brasil, 1990). Nas estruturas do SINASE, o psicólogo compõe obrigatoriamente a equipe multidisciplinar da unidade de atendimento socioeducativo, seja nos Centros Especializados de Assistência Social (CREAS), 
seja nas unidades de cumprimento de privação de liberdade, sendo um dos profissionais responsáveis pelo acompanhamento técnico dos adolescentes (CFP, 2010). O profissional está diante de um sistema amplo que envolve o adolescente, sua saúde integral, seu processo judicial, suas relações sociais e familiares e seu processo disciplinar e educacional. $O$ compromisso e a responsabilidade social da presença do psicólogo nesse contexto podem resultar em uma intervenção crítica e transformadora na situação do adolescente que cometeu ato infracional, implicando analisar o contexto social, a demanda por sua presença e a contribuição na política de atendimento ao adolescente (CFP, 2010).

O atendimento em grupo com os adolescentes em privação de liberdade oferece uma possibilidade ao psicólogo de trabalhar as demandas pessoais, coletivas e institucionais de maneira mais dinâmica e por meio de técnicas que permitem a emergência do compartilhamento, da identificação e da alteridade. Além disso, facilita a troca de experiências entre os adolescentes de forma coordenada, permitindo a ressignificação das mesmas através da mediação do psicólogo. É nesse sentido que o Departamento de Atendimento Socioeducativo de Santa Catarina prevê, em normas complementares, o atendimento de grupo como função dos psicólogos das unidades ${ }^{1}$.

Esse tipo de atendimento psicológico exibe algumas peculiaridades, principalmente quando o público-alvo é composto por adolescentes em privação de liberdade, o que demanda dos profissionais um amplo conhecimento teórico e técnico. O período de desenvolvimento em que se encontram os adolescentes é aspecto relevante para utilizar como facilitador do trabalho grupal. A tendência dos adolescentes em formarem grupos, isto é, a procura por iguais, pelo sentimento de pertença, refúgio e segurança (Azevedo \& Mello, 2009), emerge como uma característica essencial para o processo grupal e tende a facilitar a aceitação dos adolescentes para esse tipo trabalho. Assim, a proposta de trabalho em grupo com adolescentes que estão passando pela situação de internação, os quais vêm de vivências muito parecidas com as drogas e a violência, por exemplo, pode acentuar ainda mais o papel que o grupo já exerce para os adolescentes, quando este é utilizado como lugar de externalização dos sentimentos, emoções, angústias e expectativas (Azevedo \& Mello, 2009).

Fazendo um paralelo com os estudos de Winck e Strey (2009), os quais trabalham com grupos de homens autores de violência de gênero, enfatiza-se que um dos principais instrumentos de transformação é a palavra; pois elas têm força. Através delas são transmitidos todos os valores e signos que influenciam desde padrões relacionais individuais até a complexidade de uma sociedade. Assim, é justamente por essa força que os autores argumentam que por meio do trabalho grupal "a interação proporcionada por esta atividade pode ser capaz de

${ }^{1}$ http://www.dease.sc.gov.br/documentos 
instituir um real processo de reflexão e, posterior transformação em todos os envolvidos - coordenador e participantes - acerca dos diversos aspectos subjetivos ali intrínsecos" (Winck \& Strey, 2009, p. 145). No processo grupal, a cada sujeito presente é oportunizado vivenciar a diversidade de significados e percepções sobre si, proporcionado mudanças e desenvolvimento de novas formas de ver e vivenciar determinadas questões (Beiras, 2009). Além disso, a importância e o lugar que cada um ocupa no contexto global são ressaltados através da participação do grupo, a qual permite colocar o imediato, o cotidiano, o individual e o parcial dentro do histórico, do social, do coletivo e do estrutural (Azevedo \& Mello, 2009).

\section{MÉTODO}

A proposta de realização do grupo na instituição de internação de adolescentes surgiu após a verificação da existência de queixas semelhantes apresentadas pelos adolescentes no atendimento psicológico individual, bem como a necessidade de proporcionar uma integração entre eles enquanto grupo de pares e utilizar o meio institucional como recurso para o trabalho socioeducativo. Assim, foram planejados encontros grupais sob a matriz teórica sócio-histórica, compreendendo o grupo como mediador entre particularidades, singularidades dos sujeitos e a totalidade social, pois realiza a mediação entre os indivíduos e a formação social de que participam. Dessa forma, cada participante é considerado um representante de si mesmo e da história da sociedade em que vive. Além disso, as características do grupo são entendidas como um movimento contínuo, em equilíbrio instável e temporário e de extrema complexidade (Andaló, 2006).

Os elementos emergentes no grupo são significativos tanto em um nível individual quanto grupal, e as interpretações são dadas através da dialética grupo-indivíduo. Assim, a coparticipação dos adolescentes na interpretação dos dados trazidos no grupo é relevante e considerada, de forma que sejam valorizadas as expressões e reações no setting grupal. A proposta de trabalho foi oferecida como uma "via de mão dupla" na qual os adolescentes seriam corresponsáveis pelo tema da reflexão juntamente com as facilitadoras.

O relato aqui apresentado é resultado da experiência dos cinco primeiros encontros do grupo com adolescentes em cumprimento de medida socioeducativa de privação de liberdade da ala masculina de um Centro de Atendimento Socioeducativo, no qual duas das autoras, estagiárias de Psicologia, atuaram com uma intervenção em grupo. Os encontros foram realizados no espaço de convivência da ala masculina. O setting era organizado com tapetes em círculo, para que a atividade fosse realizada no chão, visando proporcionar um ambiente descontraído e mais acolhedor. 
$\mathrm{Na}$ época em que se iniciou a atividade em grupo, a instituição contava com doze adolescentes, sendo que dez participaram de ao menos um encontro. O horário escolhido para a atividade coincidia com o período de escolarização de alguns adolescentes. Uma vez que a escolarização é obrigatória para todos, apenas os que tinham aula no contra turno do grupo podiam participar. Tendo isso em vista, participaram cerca de quatro adolescentes por encontro. Esses, planejados sob supervisão acadêmica e local, iniciaram no mês de abril de 2017, com frequência semanal e duração de aproximadamente uma hora.

Alguns cuidados relativos à dinâmica grupal precisaram ser tomados, tendo em vista que os adolescentes participantes convivem diariamente entre si na instituição. Esse perfil de convivência exigiu o estabelecimento de um contrato de grupo, no qual foi preconizado o respeito pela fala do outro, a colaboração e o sigilo, sempre na medida do que era possível para os participantes. Além disso, todos os conflitos emergidos durante o processo grupal eram encorajados a serem explicitados verbalmente e sua resolução era buscada ainda naquele espaço, com o objetivo de evitar situações de inimizades entre os adolescentes e possibilitar a acolhida de suas tensões.

Ao longo das semanas, as técnicas utilizadas para atingir os objetivos de cada encontro foram diversificadas e adaptadas ao perfil individual de cada adolescente que compunha o grupo. A partir do segundo encontro, por exemplo, foi observado que a participação das coordenadoras através de alguns relatos pessoais e da disponibilidade em participar das atividades propostas permitiu uma maior aproximação com os adolescentes, que passaram a fornecer relatos mais íntimos e mais sinceros. Naturalmente, foi necessário limitar essa participação de forma com que os papéis (coordenadoras-participantes) no grupo não se confundissem. Tal trabalho foi feito de maneira sútil e progressiva, ora permitindo a condução das discussões pelos adolescentes, ora retornando às coordenadoras. Os principais temas trabalhados foram planejados de maneira com que pudessem abrir espaço para relatos pessoais e outros assuntos relacionados, permitindo-os que expressassem livremente seus pensamentos e sentimentos. Dessa forma, a temática trabalhada em cada encontro dependia dos temas emergentes do encontro anterior. Sendo assim, foram trabalhados os seguintes temas: a expectativa da saída temporária, tanto para quem iria sair quanto para quem permaneceria na unidade naquele período; o trabalho em equipe, visando engajar todos os adolescentes a participarem de diferentes formas; o retorno da saída temporária; e o uso e abuso de álcool e outras drogas.

O papel das estagiárias de Psicologia enquanto mediadoras do processo grupal era escutar os relatos dos adolescentes e transformá-los em temáticas para discussões mediadas por perguntas disparadoras e/ou reflexivas. A partir das contribuições dos adolescentes emergiram temas que colocou em questão o lugar ocupado pela Psicologia dentro de tais instituições e, mais especificamente, 
o papel do psicólogo frente à problemática dos adolescentes em conflito com a lei e ao contexto no qual eles estão inseridos.

\section{RESULTADOS}

O primeiro encontro de grupo com os adolescentes foi planejado de maneira com que fosse possível apresentar a proposta do trabalho grupal e promover uma aproximação maior entre os adolescentes e as coordenadoras. Assim, com tema livre, os adolescentes puderam expressar abertamente os assuntos que mais os preocupavam.

As dinâmicas individuais de cada adolescente e o perfil aberto do grupo fizeram com que cada encontro contasse com atividades diferenciadas. Assim, trabalhou-se com a possibilidade de integração de cada adolescente, a partir do que cada um era capaz de fornecer e abrir no contexto grupal. Para o segundo encontro, por exemplo, no qual o número de participantes se reduziu pela metade devido à saída temporária de alguns adolescentes da unidade, utilizou-se uma atividade de resolução de problemas e cooperação. Assim, considerando que um dos três adolescentes presentes não tinha o hábito de realizar as atividades reflexivas e participar verbalmente, foi levada uma tarefa manual, na qual os adolescentes precisariam se comunicar unicamente para construir objetos com palitos de madeira. Foi possível, então, contar com a participação deste adolescente tanto quanto a dos outros, e o fechamento foi voltado para a valorização do trabalho realizado coletivamente e da comunicação positiva entre eles. O grupo, embora com perfil aberto, foi se tornando muito coeso e exibindo uma identidade grupal a partir da qual foi possível o relato de cada experiência e o exercício da empatia. Os adolescentes passaram a se tornar cada vez mais empáticos e implicados nos relatos uns dos outros, o que favoreceu a condução das discussões pelas mediadoras. Assim, o quinto encontro, que assumiu um caráter mais celebrativo com a produção coordenada e compartilhada de um lanche, marcou o início de uma nova etapa para aqueles adolescentes, os quais estavam muito perto de receberem progressão de medida e voltarem para suas cidades.

Sobre os assuntos trabalhados, foi percebida a necessidade entre os adolescentes de relatarem suas experiências com drogas, violência e tráfico, aspectos que constituem o que chamam de "mundo do crime", que é percebido por eles como paralelo ao mundo real. Embora as experiências de cada um fossem muito diferentes, vários aspectos se assemelhavam quando em contato aos sentimentos relacionados a esse "mundo do crime", dos quais a excitação, o poder e o temor pela vida se destacavam nos discursos.

Buscou-se dar visibilidade às questões relativas ao "mundo do crime" ressaltando a reflexão sobre suas consequências tanto em nível pessoal quanto familiar e social. Percebeu-se que o discurso dos adolescentes se transformava 
quando instigados a falar sobre as consequências das decisões que tomaram ao longo da vida, assumindo um caráter moralista e repetitivo, ecoando concepções que são tipicamente reproduzidas pelas instituições de segurança e pela mídia. Observou-se que por meio dessa estratégia os adolescentes eram capazes de discutir sobre seus próprios atos de forma distanciada, muitas vezes na terceira pessoa, construindo relatos não muito implicados. Nesses momentos a intervenção das mediadoras voltava-se para a tentativa de aproximá-los do discurso que reproduziam por meio de perguntas reflexivas, fazendo-os pensar a partir da própria implicação. Esse movimento foi necessário para que o grupo não se tornasse mais um elemento reprodutor dos discursos hegemônicos que incidem sobre as vivências desses adolescentes e dos quais eles se esquivam.

O contexto grupal também foi espaço para o compartilhamento das experiências de violências que cada adolescente presenciou quando em liberdade, muitas delas relacionadas com o sofrimento e morte de familiares por decorrência do envolvimento com as drogas ilícitas, como cocaína, crack e LSD. Foi percebido que os adolescentes se mostravam ansiosos e temerosos ao contar suas experiências, sentimentos que não conseguiam acessar e compreender conscientemente, o que demonstravam evitando conversar sobre eles durante os encontros. Em um dos encontros, durante uma discussão sobre a morte de amigos por grupos do tráfico de drogas, dois adolescentes resistiram em exibir como estavam vivendo o luto, preferindo justificar o porquê da morte deles. A seguir, um recorte da fala de um dos adolescentes exemplifica: "Quem morre sem fazer nada errado merece o luto, quem tem dívida e morre por isso, não".

Além da sua relação com as drogas e o crime, os adolescentes conversaram sobre seus relacionamentos com esposas e namoradas, também permeados por regras estabelecidas no contexto do crime e da violência. Evidenciaram, em seus discursos, que entre o homem e a mulher deve existir confiança, mesmo que o homem seja preso, ocasião na qual a mulher deve visitá-lo sempre e permanecer fiel. Em caso de traição, a mulher merece sofrer consequências, e o homem traído é autorizado a matá-la quando sair da prisão, assim como poderá matar o homem com o qual ela o traiu. Por outro lado, os adolescentes não argumentaram que isso deveria acontecer caso a pessoa presa fosse uma mulher, relatando apenas que seria justificável se acontecesse. Assim, a fidelidade da mulher para com seu namorado ou marido é muito valorizada, como a autoridade do homem sobre a mulher. Nesse momento, um dos adolescentes resumiu a discussão, dizendo: "Mulher mata mais que arma".

A intervenção das mediadoras ao longo das discussões produzidas pelos adolescentes visava ampliar o repertório de possibilidades, principalmente em relação a assuntos nos quais se evidenciavam estereótipos, preconceitos, machismo e violação de direitos humanos. No caso da fidelidade entre casais, a apresentação de situações hipotéticas com a inversão dos papéis entre o homem 
e a mulher produziu o aprofundamento e maior reflexão por parte dos adolescentes.

\section{DISCUSSÃO}

Com a inserção do psicólogo como parte de equipes multidisciplinares em várias instituições de atendimento ao público, como escolas, postos de saúde, hospitais e centros de referência em Assistência Social, torna-se cada vez mais imperativo a disponibilidade e competência do profissional para trabalhos em grupo e em grupoterapias (Schmitt et al., 2016; Costa, 2016). Nos centros de atendimento socioeducativo, portanto, essa necessidade é igualmente presente.

O trabalho do psicólogo com adolescentes em privação de liberdade é frequentemente caracterizado pelo atendimento de uma série de demandas institucionais, como o acompanhamento dos processos judiciais e elaboração de relatórios, sendo que a atuação direta com os adolescentes se reduz para o atendimento dos casos mais emergenciais (Santos \& Menandro, 2017). Tendo em vista a sobrecarga dos profissionais que atuam em um sistema de alta rotatividade de adolescentes, o trabalho de grupo com essa população se torna desafiador e requer uma alta disponibilidade para confrontar as institucionalidades e pôr à prova sua própria atuação.

Um dos primeiros desafios enfrentados pode ser a falta de um colega profissional que possa ser coterapeuta ou facilitador em conjunto, tendo em vista que geralmente as equipes multidisciplinares em Centros de Atendimento Socioeducativo (CASEs) não contam com profissionais suficientes para dar conta das demandas mais básicas (Santos \& Menandro, 2017). Assim, torna-se útil o alinhamento de objetivos com profissionais de outras áreas, como assistentes sociais e pedagogos, ou a abertura de campos de estágio em Psicologia, como maneira de viabilizar o trabalho de grupo com os adolescentes. Justifica-se a necessidade de uma dupla de coordenadores no trabalho de grupo com adolescentes privados de liberdade por compreender que, assim, as demandas são melhor acolhidas, a possibilidade de vinculação dos participantes se amplia, o controle sobre aspectos objetivos como tempo e disposição de materiais é dividido, e se torna duas vezes maior a capacidade de apreender todos os aspectos da dinâmica grupal de cada encontro. Além disso, procura-se trabalhar com o maior número de adolescentes possível, o que às vezes pode significar um grupo de dez ou doze participantes, para o qual é indispensável a presença de dois coordenadores.

Outro aspecto que coloca à prova o trabalho em grupo com adolescentes nessa condição é a voluntariedade para esse tipo de atividade. O contexto dos CASEs é permeado pela obrigação dos adolescentes em participarem das atividades educativas e recreativas que são "oferecidas" pela equipe multidisciplinar. Conforme Rosário (2010), a disponibilidade dos adolescentes em 
participar das atividades obrigatórias nessas instituições contribui para o bom funcionamento da unidade e para que os relatórios individuais sejam positivos, o que se reflete nas liberações. No entanto, entende-se que as atividades realizadas compulsoriamente apresentam resultados no sentido da disciplina e docilização dos adolescentes, enquanto a disponibilidade para atividades voluntárias possibilita o pensamento crítico e o movimento de conscientização e implicação. Por isso, a participação voluntária é indispensável para o alcance dos efeitos positivos provocados pelo trabalho em grupo, assim como o é em psicoterapias individuais.

O papel do psicólogo na coordenação de grupos com adolescentes, principalmente no contexto de privação de liberdade, se caracteriza pela disponibilidade para ouvir, refletir e fornecer, no contexto grupal e fora dele, uma atenção cuidadosa com cada adolescente, compreendendo suas histórias de vida e modos de ser (Perfeito, 2005). A reflexão sobre a prática profissional no contexto específico de atuação com adolescentes em cumprimento de medida socioeducativas é essencial para a percepção de que um atendimento personalizado não significa, necessariamente, atendimento individualizado, o que permite a ampliação dos métodos de atuação do psicólogo e evita tornar a experiência da privação de liberdade em uma vivência sem vínculos.

Acerca do processo grupal entende-se, conforme Andaló (2006), que o coordenador do grupo deve-se fazer intérprete dos dados emergentes, sendo capaz de enxergar os participantes tanto como indivíduos quanto como integrantes de um movimento coletivo e "ver o possível com olhos comuns" ( $p$. 79). Nesse contexto, a autora recomenda que o coordenador seja capaz de estabelecer uma relação horizontal com o grupo, permitindo-se ser co-autor do processo grupal e delegando a todos no grupo a função de co-investigadores, destacando que todos os participantes estão igualmente implicados tanto no processo quanto na reflexão do mesmo (Andaló, 2006).

Assim, entende-se importante para a coordenação de grupo com adolescentes em privação de liberdade o reconhecimento das histórias e experiências dos participantes, principalmente quando não há nenhuma experiência prévia com pessoas em situação de vulnerabilidade, pobreza ou violência, evitando uma atuação conservadora que vai de encontro com o os objetivos elencados para o trabalho grupal com os adolescentes (Gallo, 2008; Santos \& Menandro, 2017). Isso, no entanto, não significa deixar de pontuar e fazer refletir sobre alguns aspectos que os adolescentes trazem em relação a temáticas polêmicas e que ferem, muitas vezes, os direitos humanos. Trata-se de uma postura ética que o profissional deve assumir, cujo objetivo central é proporcionar o espaço de acolhida, discussão e reflexão. Nesse sentido, Andaló (2006) afirma que qualquer uma dessas ações consiste numa análise do que já passou e não se pode prever o que virá a acontecer, uma vez que tudo que é comentado terá consequências em no movimento subsequente do grupo, 
modificando suas etapas posteriores, ou seja, qualquer pontuação ou interpretação altera os rumos do processo grupal.

Além do conhecimento teórico e do saber apreendido a partir da atuação de outros profissionais, é indispensável ser capaz de abrir-se para as contribuições que os adolescentes fornecem e utilizá-las como fonte de informações para o desenvolvimento do grupo. Isso significa estar atento às formas como os adolescentes se comunicam a aos aspectos não verbais de sua comunicação, que deixam transparecer o humor, as sensações e as possibilidades de reflexão.

No tocante às contribuições aos adolescentes dessa proposta de trabalho, considera-se que a promoção de um espaço de diálogo e trocas de experiências permite o desenvolvimento de habilidades sociais (Silva \& Murta, 2009) e interpessoais e a aproximação com conteúdos relevantes para a criação de novas possibilidades de vida durante e após o período de internação. Além disso, é facilitador da ressignificação das trajetórias de vida e da medida socioeducativa de privação de liberdade (Perfeito, 2005). Nesse sentido, o incentivo a fala e o exercício da escuta uns dos outros contribuem para a identificação, mas também para o reconhecimento da diferença entre as pessoas que são colocadas em um lugar em comum, o dos autores de atos infracionais. Os adolescentes demonstraram muita disposição para falar e contar a suas histórias, o que no início resultou em todos falando ao mesmo tempo e pouco ouvindo o que os outros tinham a dizer. Com o decorrer dos encontros a dinâmica grupal foi ajustada às demandas dos adolescentes e o falar e o ouvir se harmonizaram. Com isso, acredita-se que a possibilidade de trabalhar em grupo possibilitou constituir um espaço de vínculos, identificações e a busca de potenciais individuais e coletivos (Schmitt et al., 2016; Costa, 2016).

De modo geral, o trabalho em grupo rompe com a ideia de como a medida socioeducativa é entendida pelos adolescentes, unicamente punitiva, e indica seu caráter socioeducativo, ressaltando a importância de práticas alternativas, pensando na superação do estigma de fracasso atribuído aos adolescentes e ao próprio sistema socioeducativo. É o espaço por excelência para usar o potencial dos jovens já desacreditados por muitos (Schmitt et al., 2016; Costa, 2016).

\section{CONSIDERAÇÕES FINAIS}

O SINASE foi um importante passo para a consolidação de uma estratégia de atenção e cuidado interdisciplinar com a adolescência brasileira, embora ainda exista um longo caminho a ser percorrido. O olhar da Psicologia sobre as dinâmicas subjetivas e inter-relacionais presentes no contexto de privação de liberdade de adolescentes se torna indispensável para a personalização da medida socioeducativa e para a expressão das potencialidades individuais desses jovens. Nesse sentido, o método de intervenção psicológica em grupo apresenta- 
se como uma das experiências de produção de sentidos mais ricas nesses espaços marcados pela disciplina e moral, apontando para um horizonte de possibilidades aos adolescentes.

Para além disso, a experiência de mediação de grupo de adolescentes no contexto da privação de liberdade adquire um contorno de estratégia diferenciada e especializada, que envolve responsabilidade, disponibilidade e liberdade para expressão. Sob esses aspectos, é possível construir uma prática ética e transformadora tanto para os profissionais quanto para os adolescentes, restaurando vínculos positivos com um sistema historicamente repressor.

\section{DECLARAÇÃO DE CONFLITOS DE INTERESSE}

As autoras do manuscrito intitulado "O trabalho do psicólogo com grupo de adolescentes em privação de liberdade" declaram que não possuem conflito de interesse de ordem: financeira, comercial, política, acadêmico e/ou pessoal. Declaram também que o estudo foi realizado com financiamento próprio, sem a participação de agências de fomento.

\section{REFERÊNCIAS}

Andaló, C. (2006). Mediação grupal: Uma leitura histórico-cultural. São Paulo, SP: Agora.

Azevedo, M. R. D. \& Mello, V. M. R. M. (2009). Trabalhando em grupo com adolescentes. São Paulo, SP: Atheneu.

Bazon, M. R., Silva, J. L., \& Ferrari, R. M. (2013). Trajetórias escolares de adolescentes em conflito com a lei. Educação em Revista, 29(2), 175-199. doi: $10.1590 / S 0102-46982013000200008$

Beiras, A. (2009). Grupos de homens autores de violência: Possibilidades de intervenção diante das recomendações propostas na Lei Maria da Penha. In S. L. R. Rovinski \& R. M. Cruz. (Eds.), Psicologia Jurídica: Perspectivas teóricas e processos de intervenção (pp.129-144). São Paulo, SP: Vetor.

Brasil. (1990). Lei No 8.069, de 13 de julho de 1990. Dispõe sobre o Estatuto da Criança e do Adolescente e dá outras providências. Brasília, DF.

Brasil. (2012). Lei No 12.594, de 18 de janeiro de 2012. Institui o Sistema Nacional de Atendimento Socioeducativo (Sinase), regulamenta a execução das medidas socioeducativas destinadas a adolescente que pratique ato infracional e dá outras providências. Brasília, DF.

Brasil. Presidência da República. Secretaria de Direitos Humanos (SDH). (2017). Levantamento Anual SINASE 2014. Brasília, DF: Secretaria de Direitos Humanos. Recuperado em 02 de janeiro de 2018, de http://www.sdh.gov.br/noticias/pdf/levantamento-sinase-2014 
Carvalho, V. A. \& Silva, M. R. F. (2011). Política de segurança pública no Brasil: Avanços, limites e desafios. Revista Katálysis, 14(1), 59-67. doi: $10.1590 /$ S1414-49802011000100007

Castel, R. (1997) A dinâmica dos processos de marginalização: Da vulnerabilidade à "desfiliação". Cadernos $C R H, 26,19-40$. Recuperado em 02 de janeiro de 2018, de https://portalseer.ufba.br/index.php/crh/article/view/18664

Conceição, M. I. G, Penso, M. A., Costa, L. F., \& Carreteiro, T. C. O. (2016). Uma intervenção com adolescentes em conflito com a lei a partir da construção do método de história de vida. Nova Perspectiva Sistêmica, 25(55), 46-63. Recuperado em 01 de janeiro de 2018, de http://www.revistanps.com.br/index.php/nps/article/view/135

Conselho Federal de Psicologia (2010). Referências técnicas para atuação de psicólogos no âmbito das medidas socioeducativas em unidades de internação. 36 p. Brasília, DF: Conselho Federal de Psicologia.

Costa, J. F. C. (2016). O trabalho de grupo como contexto de promoção de cooperação na Educação Pré-Escolar. (Dissertação de mestrado). Universidade do Minho, Braga, Portugal.

Ferrão, I. S., Santos, S. S., \& Dias, A. C. G. (2016). Psicologia e Práticas Restaurativas na Socioeducação: Relato de Experiência. Psicologia: Ciência e Profissão, 36(2), 354-363. doi:10.1590/1982-3703000122014

Frota, A. M. M. C. (2007). Diferentes concepções da infância e adolescência: a importância da historicidade para sua construção. Estudos e Pesquisas em Psicologia, 7(1), 147-160.

Gallo, A. E. (2008). Atuação do psicólogo com adolescentes em conflito com a lei: A experiência do Canadá. Psicologia em Estudo, 13(2), 327-324.

Gomes, C. C. \& Conceição, M. I. G. (2014). Sentidos da trajetória de vida para adolescentes em medida de liberdade assistida. Psicologia em Estudo, 19(1), 47-58. doi:10.1590/1413-7372189590005

Guareschi, N. M. F., Reis, C. D., Huning, S. M., \& Bertuzzi, L. D. (2007). Intervenção na condição de vulnerabilidade social: Um estudo sobre a produção de sentidos com adolescentes do programa do trabalho educativo. Estudos e pesquisas em Psicologia, 7(1), 20-30.

Mourão, A. N. M. \& Silveira, A. M. (2014). Controle social informal e a responsabilização de jovens infratores. Caderno $C R H, 27(71), 393-413$. doi: 10.1590/S0103-49792014000200011

Nardi. F. L., \& Dell'Aglio, D. D. (2014). Trajetória de adolescentes em conflito com a lei após cumprimento de medida socioeducativa em meio fechado. Psico, 45(4), 541-550.

Pereira, M. R., \& Gurski, R. (2014). A adolescência generalizada como efeito do discurso do capitalista e da adultez erodida. Psicologia \& Sociedade, 26(2), 376-383. 
Perfeito, D. M. (2005). Adolescentes infratores: Uma aprendizagem e uma luz na psicoterapia - relato de prática profissional. Psicologia para América Latina, (4).

Rosário, A. B. (2010). Grupo com adolescentes em privação de liberdade: Circulação da palavra como possibilidade de ressignificação do ato infracional. Revista SPAGESP, 11(1), 66-76.

Santos, M. N., \& Menandro, M. C. S. (2017). Atuação profissional junto aos adolescentes em medida socioeducativa de internação: Um estudo com psicólogos. Interação em Psicologia, 21(2). doi:10.5380/psi.v21i2.34081

Silva, M. P., \& Murta, S. (2009). Treinamento de habilidades sociais para adolescentes: uma experiência no programa de atenção integral à família (PAIF). Psicologia: Reflexão e Crítica, 22(1), 136-143. doi:10.1590/S010279722009000100018

Silva, R. (2015). A eficácia sociopedagógica da pena de privação de liberdade. Educação e Pesquisa, 41(1), 33-48. doi:10.1590/S1517-97022015011381

Schmitt, A. A., Nascimento, D. M., \& Schweitzer, L. (2016). Grupo com adolescentes em cumprimento de medida socioeducativa de liberdade assistida: Relato da experiência em um centro de referência especializado em assistência social. Pesquisas e Práticas Psicossociais, 11(2), 399-411.

Tomasi, L. O. \& Macedo, M. M. K. (2015). Adolescência em conflito com a lei: A intensidade da história de vida em ato. Psicologia: Teoria e Pesquisa, 31(1), 53-63. doi:10.1590/0102-37722015011723053063

Véras, M. P. B (2001). Exclusão Social - um problema brasileiro de 500 anos (notas preliminares). In B. Sawaia (Ed.), As artimanhas da exclusão (pp. 27-50). Petrópolis, RJ: Editora Vozes.

Waiselfisz, J. J. (2014). Mapa da violência 2014: Os jovens do Brasil. Brasília, DF: Centro Brasileiro de Estudos Latino-Americano.

Waiselfisz, J. J. (2015). Mapa da violência 2015: Adolescentes de 16 e 17 anos do Brasil. Brasília, DF: Centro Brasileiro de Estudos Latino-Americano.

Winck, G. E., \& Strey, M. N. (2009). "Palavra de pulso firme": A coordenação de grupos com homens acusados de violência de gênero enquanto agente reflexivo e transformador. In: S. L. R. Rovinski \& R. M. Cruz. (Eds.), Psicologia Jurídica: Perspectivas teóricas e processos de intervenção. (pp.145-158). São Paulo, SP: Vetor. 
Sobre as autoras

Giulia Oliva Grassi é psicóloga formada pela Universidade Federal de Santa Catarina e mestranda do Programa de Pós-Graduação em Psicologia na Universidade Federal de Santa Catarina. giuliagrassi46@gmail.com Beatriz Pires Coltro é psicóloga formada pela Universidade Federal de Santa Catarina e mestranda do Programa de Pós-Graduação em Psicologia na Universidade Federal de Santa Catarina. beatrizpcoltro@gmail.com Andréia Isabel Giacomozzi é psicóloga formada pela Universidade Federal de Santa Catarina, Mestre e Doutora em Psicologia pela Universidade Federal de Santa Catarina, Professora do PPGP UFSC e do Departamento de Psicologia da UFSC, membro do LACCOS- Laboratório de Psicologia Social da Comunicação e Cognição. agiacomozzi@hotmail.com

Tathiana Reche Santa Rosa é psicóloga formada pela Universidade Paulista Objetivo (UNIP) Mestre em Ciências da Educação pelo Instituto Superior de Educação Lúcia Dantas e atua no Departamento de Administração Socioeducativo de Santa Catarina- DEASE. santarosapsic@yahoo.com.br

Giulia e Beatriz contribuíram para a conceitualização, investigação e visualização do artigo, realizaram também a redação do artigo. Andréia orientou academicamente a realização do trabalho de grupo e é a responsável pela redação final (revisão e edição). Tathiana foi responsável pela supervisão local do trabalho em grupo contribuindo para o desenvolvimento das atividades aqui relatadas.

Recebido em: 04/09/2017

$1^{a}$ revisão em: 03/01/2018

Aceito em: 01/05/2018 